\title{
ENVIRONMENTAL NOISE POLLUTION FROM ROAD TRANSPORT AND OTHER SOURCES IN VARNA, BULGARIA
}

\author{
Rozalina Chuturkova $^{1}$, Maya Stefanova ${ }^{2}$, Anna Simeonova ${ }^{3}$, Veselina Bojilova ${ }^{4}$ \\ ${ }^{1}$ Associate Professor, Department of Ecology and Environmental Protection, Technical University, Varna, Bulgaria \\ ${ }^{2}$ PhD Student, Department of Ecology and Environmental Protection, Technical University, Varna, Bulgaria \\ ${ }^{3}$ Associate Professor, Department of Ecology and Environmental Protection, Technical University, Varna, Bulgaria \\ ${ }^{4}$ Research Associate, Regional Health Inspection, Varna, Bulgaria
}

\begin{abstract}
The present research has been conducted in Varna - the third biggest city in Bulgaria in order to assess the environmental noise pollution from road transport and other sources. Noise monitoring has been done during the period 2007-2014 at 45 monitoring posts situated at: areas with intensive road traffic; areas with railroad traffic; areas with aviation noise; areas with marine traffic; industrial areas; built-up areas; recreation areas; hospitals and sanatoria; scientific research sites; quiet areas in open country. The noise pollution has been assessed through the daily equivalent sound levels LeqD in the environment that determine the degree of discomfort during daytime $(07.00-19.00)$. Research results have been statistically interpreted by variation analysis and the differences have been estimated by Student-Fischer t-criteria. The dominant source of environmental noise pollution in Varna is road traffic. Sound levels at monitoring posts with intensive road traffic are considerably higher than the established limit value - LeqD vary between 69.28 and $71.72 \mathrm{~dB}(\mathrm{~A})$ and exceed the limit value with 10-12 $\mathrm{dB}(\mathrm{A})$. At recreation areas the average LeqD exceed the limit value during the entire monitoring period. More intensive noise pollution has been observed from 2010 onwards as the increase is statistically reliable and the differences are of strong statistical significance $(0.001 \leq P \leq 0.05)$. At built-up areas the average LeqD are close to the limit value and a statistically reliable increase has been registered from 2010 onwards $(P<0.001)$. Different types of measures are discussed to reduce noise pollution mostly from road transport.
\end{abstract}

Key Words: daily equivalent sound level, environmental noise pollution, noise sources, road traffic

\section{INTRODUCTION}

Pursuant to Directive 2002/49/EC of the European Parliament relating to the assessment and management of environmental noise [1] and the relevant Environmental Noise Prevention Law [2] strategic noise maps are required for all agglomerations in Bulgaria. Strategic noise mapping aims to determine the level of environmental noise pollution throughout measurement, assessment and mapping of sound levels from different sources: road traffic, railroad transport, aviation, marine transport, industrial installations in the scope of Annex 4 to Article 117, Paragraph 1 of the Environment Protection Law [3] and some local noise sources. Sound levels need to be monitored at urban areas, parks and other quiet areas in open country, hospitals, nursery schools and schools and scientific research sites as well. Strategic noise maps provide means for acoustic planning and action plan adopting based on mapping results. There is an increasing body of research relating to the process of strategic noise mapping which demonstrates the necessity of collecting data on sound levels from different sources in an agglomeration, their further interpretation and analysis along with noise pollution modeling [4-6]. A continuous monitoring is suggested in addition to the so called "quasi-periodic" monitoring (periodical measurements manually conducted for a certain period of time - from 15 to 30 minutes) in order to assess the alteration of the acoustic environment and noise pollution at urban areas [7].

Measures for environmental noise prevention and reduction need to be adopted mostly at areas where exceedingly high levels of a certain noise indicator may cause adverse impact upon human health or where sound levels do not exceed the established limit value and need to be prevented from increasing. A lot of research has been conducted on the environmental noise from road traffic and its impact upon the exposed population and results prove the appearance of annoyance, sleep disturbance and other negative effects upon human health and life standard [8-12]. The combined effect of environmental noise and particle pollution $\mathrm{PM}_{2.5}$ upon cardiovascular decease and human mortality has also been studied [13]. Environmental noise pollution is now commonly treated as a social health problem. Experts prove that environmental noise is not only a reason for annoyance but it is a potential risk for cardiovascular decease, including heart attack and brain insult [14-16, 30]. Environmental noise pollution causes over 10000 cases of untimely death due to coronary heart decease and brain insult every year. Almost $90 \%$ of environmental noise health effects are related to road traffic. Long-term exposure to noise pollution may cause severe damages to the central and the peripheral nervous system [17]. A healthy environment for the population exposed to noise pollution need to be established and this aim requires integrated approach for adopting measures to prevent or reduce noise. 
The present research aims to assess the environmental noise pollution from road traffic and other typical sources in Varna and to provide a basis for developing measures that improve and sustain the acoustic environment.

\section{MATERIAL AND METHODS}

The research has been conducted in Varna - the third biggest city in Bulgaria with population over 350000 . Varna is the biggest city in North-East Bulgaria and a municipal and district center. It is defined as a functional urban area (FUA) according the classification system of European cities. Varna municipality is the basic center of the North-East Planning Region and it is typical for its welldeveloped economy mostly related to marine industry shipbuilding, ship repairing, marine transport, and tourism. Urban noise levels have been measured at 45 monitoring posts during the period 2007-2014. The monitoring posts are situated as follows: 11 posts at intensive road traffic areas; 2 posts at railroad traffic areas; 4 posts at areas with aviation noise pollution; 1 post at marine traffic area; 13 posts at industrial areas (production plants and warehouse areas); 7 posts at built-up areas with less intensive noise pollution; 3 posts at recreation areas; 2 posts at hospitals and sanatoria; 1 post at a scientific research site; 1 post at a quiet area in open country. All monitoring posts comply with the requirements of paragraphs 5, 6 and 7 of Guideline methodology for the determination of the number, situation and spatial distribution of posts for environmental noise monitoring and the intervals for sound level measurements and Regulation No 54 relating to the functioning of the national system for environmental noise monitoring [18, 19].

Measurements of noise pollution from transport sector have been conducted by using a sound level meter Mediator 2238 (Bruel\&Kjaer, Denmark) from July to September at three time intervals: $08.00-10.00 ; 10.00-12.00 ; 17.00-19.00$. Along with the acoustic measurements data has been collected on the intensity and structure of road traffic, road surface type, ratio between built-up and green areas. Daily equivalent sound levels LeqD in the environment have been monitored in order to determine the degree of discomfort during daytime (07.00 - 19.00).

Measurement results have been statistically interpreted by variation analysis and the differences have been estimated by Student-Fischer t-criteria.

\section{RESULTS AND DISCUSSION}

Research results indicate that motor vehicles related to environmental noise pollution in Varna do not vary significantly by their type. During the period 2007-2014 the most numerous vehicle sector is the car sector $-90.2 \%$, followed by the commercial vehicle sector $-6.7 \%$ (Fig. 1). Similar researches at urban areas also indicate that the car sector is the most numerous one within the road transport structure being the major source of environmental noise pollution and a dominant emission source of various harmful substances in the atmosphere [20].

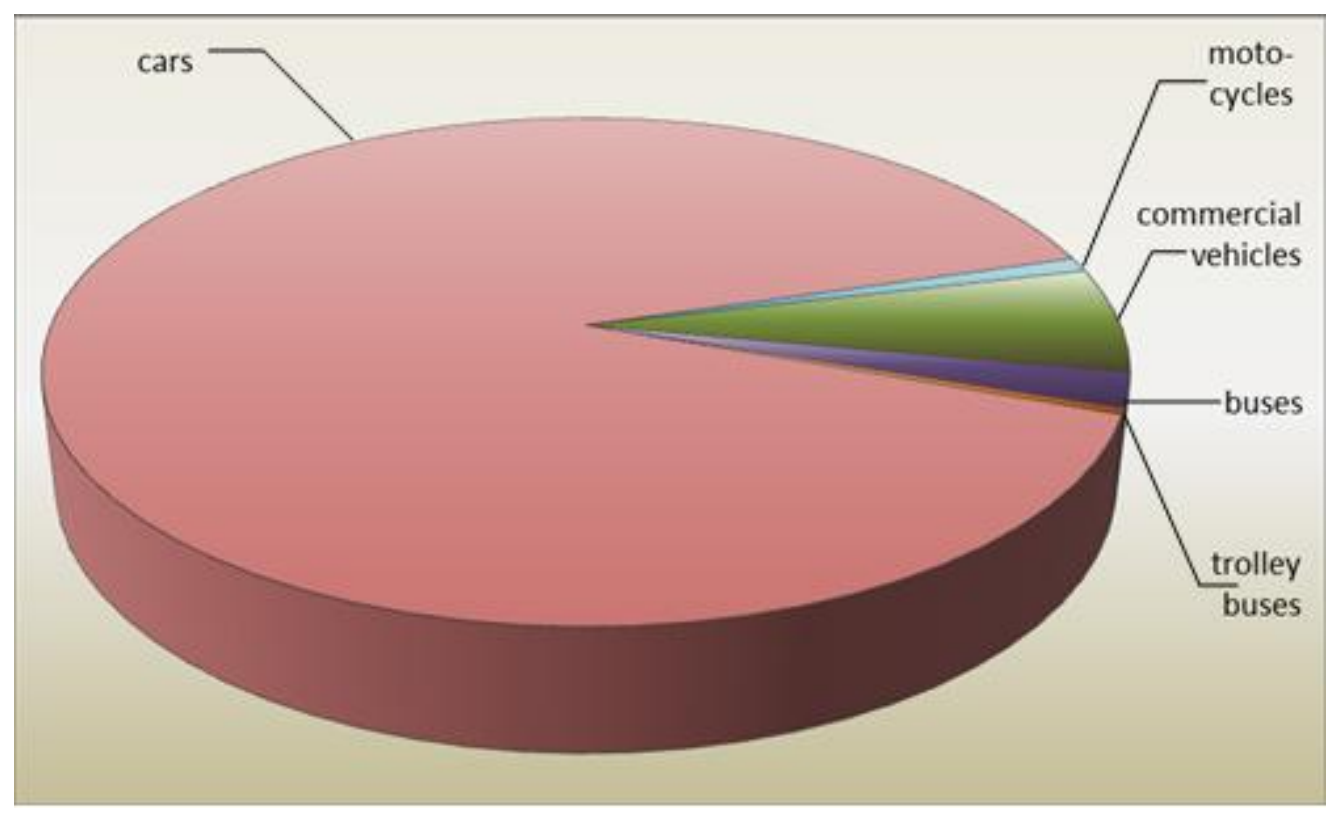

Fig. 1: Road transport structure

The intensity of road traffic does not vary significantly either. At the beginning of the monitoring period (20072010) the road traffic intensity varies from 1762 to 1965 vehicles per hour. From 2010 onwards the intensity gradually decreases to 1725 vehicles per hour in 2013 and 1660 vehicles per hour in 2014, as the differences are of weak statistical significance $(P>0.05)$ for the entire monitoring period.
The average LeqD at posts with intensive road traffic are considerably higher than the established limit value 60 $\mathrm{dB}(\mathrm{A})$ [21]. During the period 2007-2014 the average LeqD vary between 69.28 and $71.72 \mathrm{~dB}(\mathrm{~A})$ and exceed the limit value with 10-12 $\mathrm{dB}(\mathrm{A})$ (Fig. 2). High sound levels are registered due to poor traffic flow management (traffic speed and crossway traffic lights), overworked vehicles, damaged road surface with partially recovered areas. Green 
strips along the roads are not sufficient to decrease traffic noise pollution. The lack of bypass roads for transit traffic is another reason for noise pollution along with minimal distances between buildings and roads, insufficient number of parking lots and sound absorbing screens.

A certain decrease trend is registered during the period 2013-2014 compared to the noise pollution levels measured at the beginning of the monitoring period (2007-2008), as the differences are of strong statistical significance $(0.01 \leq \mathrm{P}$ $\leq 0.05)$. The decrease trend results from the registered decrease of vehicle flow intensity at the end of the monitoring period. Nevertheless, noise pollution in 2014 exceeds the established limit value. Road transport is proved to be the dominant source of environmental noise at urban areas as sound levels at major roads vary from 60.1 to 110.2 $\mathrm{dB}(\mathrm{A})[22]$.

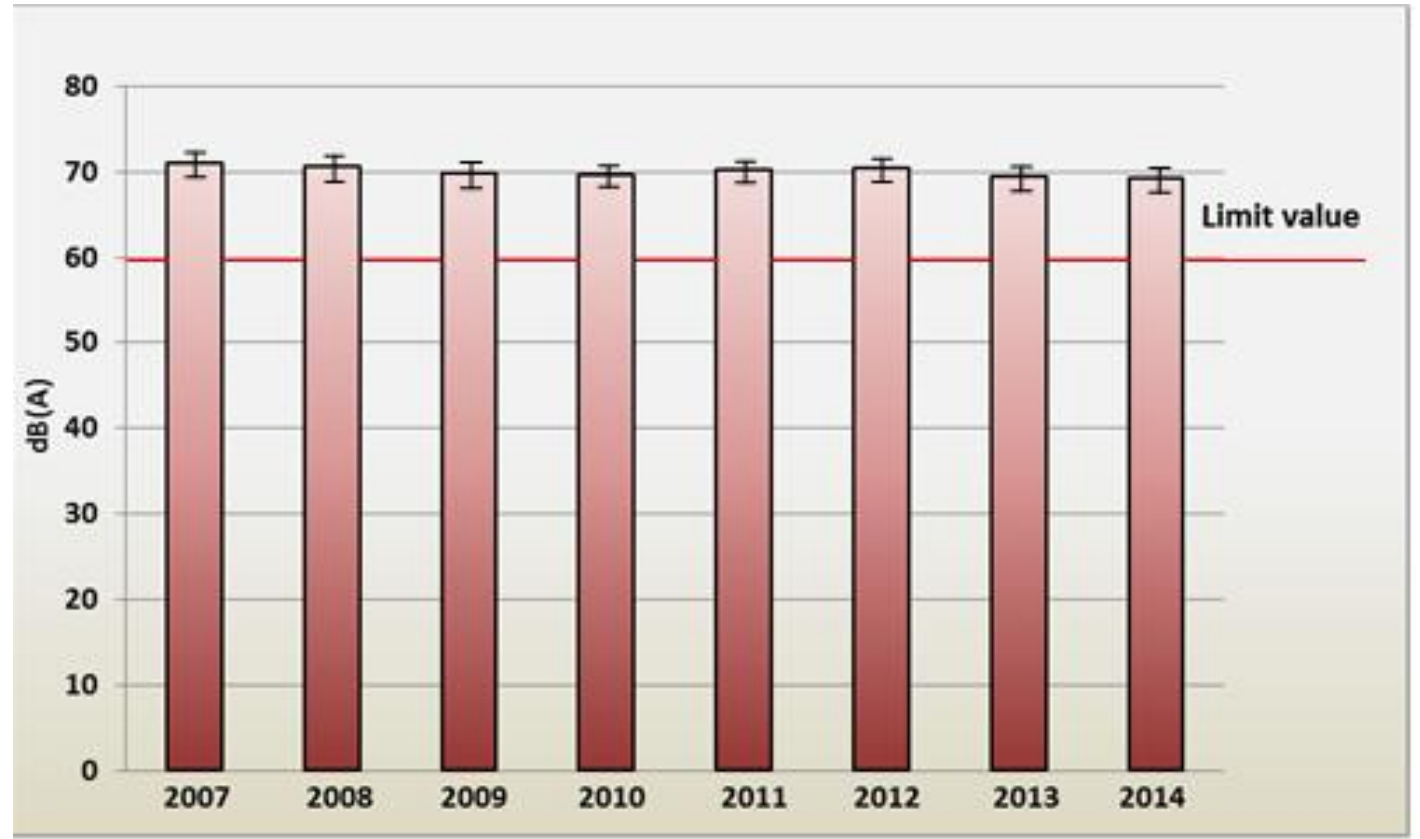

Fig. 2: Average LeqD at posts with intensive road traffic, $d B(A)$

The average LeqD at posts with railroad traffic are quite lower - they vary from 51.38 to $59.67 \mathrm{~dB}(\mathrm{~A})$ and do not exceed the established limit value $65 \mathrm{~dB}(\mathrm{~A})$ (Fig. 3). The environmental noise pollution from this source is rather stable $(\mathrm{P}>0.05)$ during the monitoring period with a few exceptions.

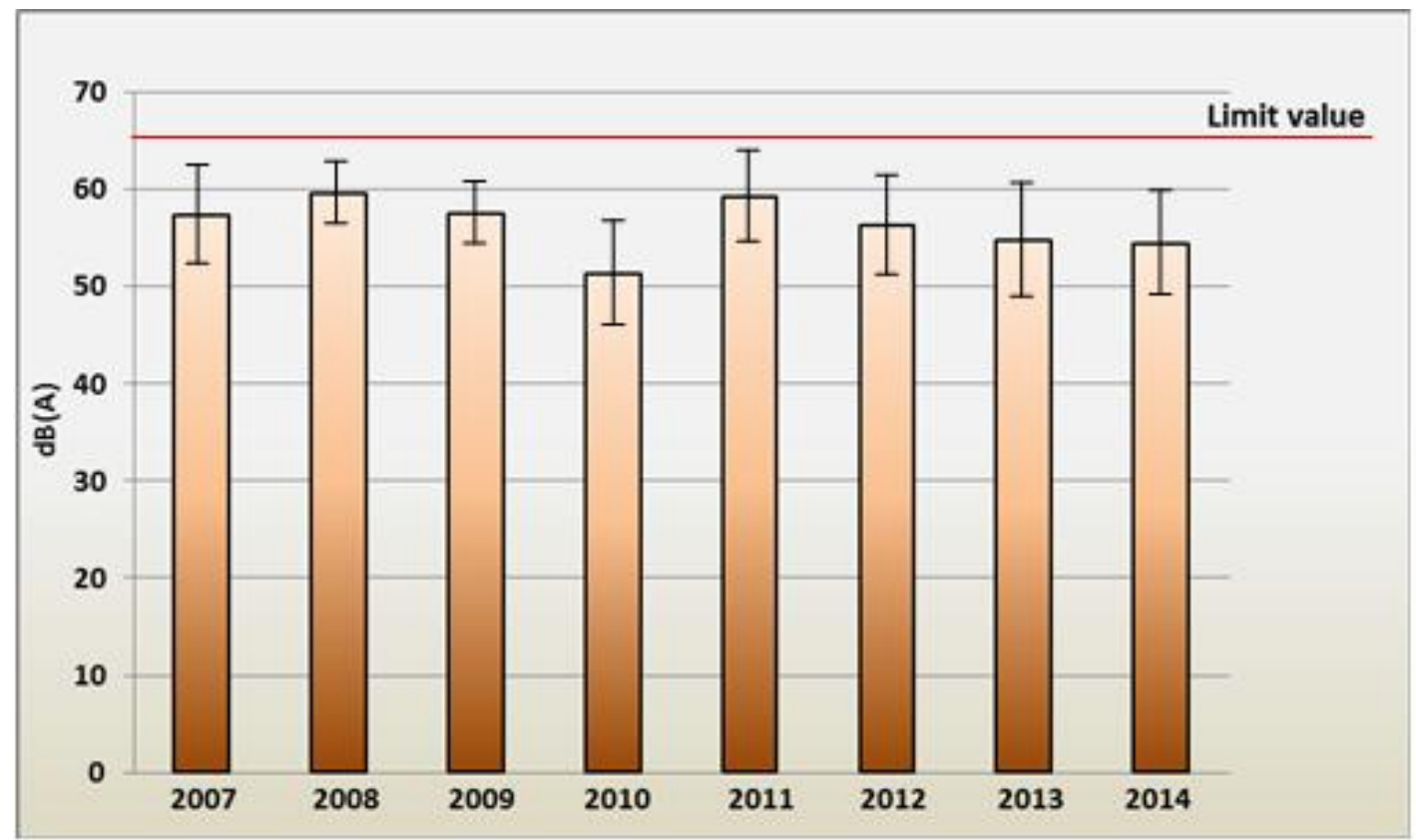

Fig. 3: Average LeqD at posts with railroad traffic, $d B(A)$ 
Similar results are registered at posts with aviation noise the average LeqD do not exceed the limit value $65 \mathrm{~dB}(\mathrm{~A})$ and vary slightly between 51.81 and $58.26 \mathrm{~dB}$ (A) (Fig. 4). A noise pollution trend is not registered. The aviation noise from Varna airport contributes to increasing the total urban noise pollution but only in certain areas and during short periods of time. Varna airport is situated $10 \mathrm{~km}$ away from the city center and $1 \mathrm{~km}$ away from a residential suburb. The acoustic discomfort caused by aviation is most intensive during summertime and most annoying during nighttime although none of the registered sound levels exceed the established limit value.

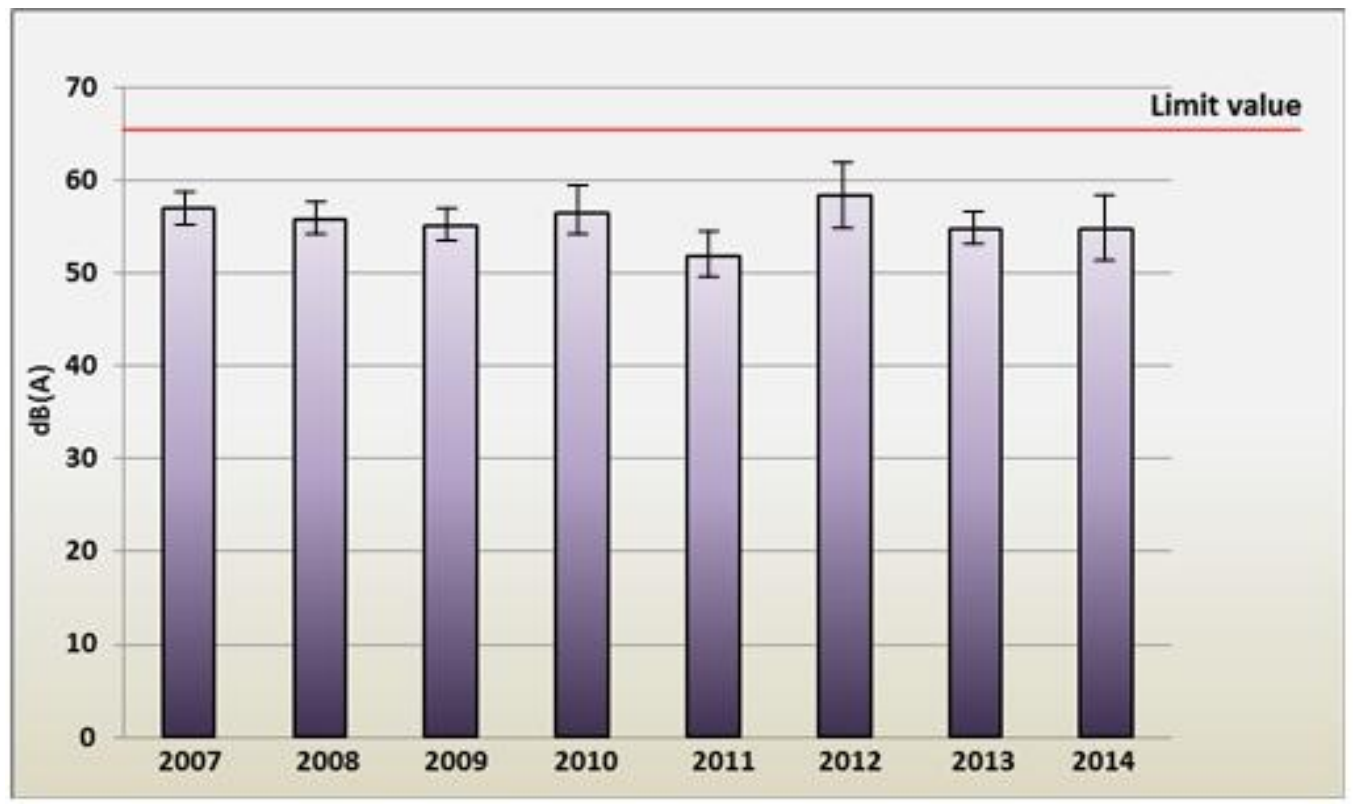

Fig. 4: Average LeqD at posts with aviation noise, $d B(A)$

Monitoring results at posts with marine transport indicate that the average LeqD exceed the limit value $65 \mathrm{~dB}(\mathrm{~A})$ during the entire monitoring period (Fig. 5). The highest values are registered in $2008-71.97 \mathrm{~dB}(\mathrm{~A})$ and during the period 2011-2013 - $70.83 \mathrm{~dB}(\mathrm{~A})$ as they exceed the established limit value with $7 \mathrm{~dB}(\mathrm{~A})$. At the end of the monitoring period (2014) the average LeqD is slightly above the limit value $-65.73 \mathrm{~dB}(\mathrm{~A})$. Differences of strong statistical significance $(0.001 \leq \mathrm{P} \leq 0.05)$ are calculated regarding the registered decrease of noise pollution levels and the variations in certain years.

The average LeqD at industrial areas (production plants and warehouse areas) are considerably lower than the established limit value $-70 \mathrm{~dB}(\mathrm{~A})$ (Fig. 6). Sound levels vary between 55.78 and $58.94 \mathrm{~dB}(\mathrm{~A})$ during the entire monitoring period and a noise pollution trend is not registered.

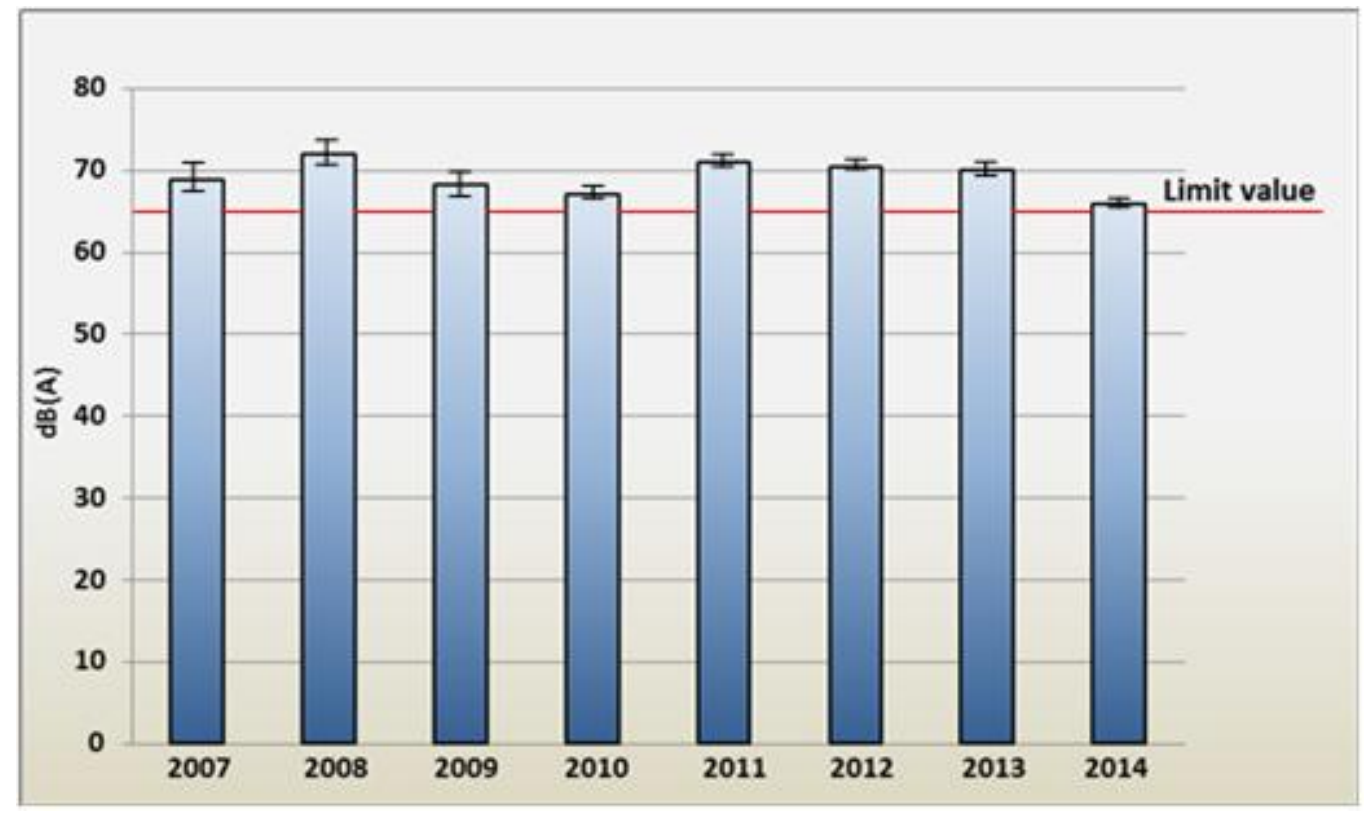

Fig. 5: Average LeqD at posts with marine transport, $d B(A)$ 


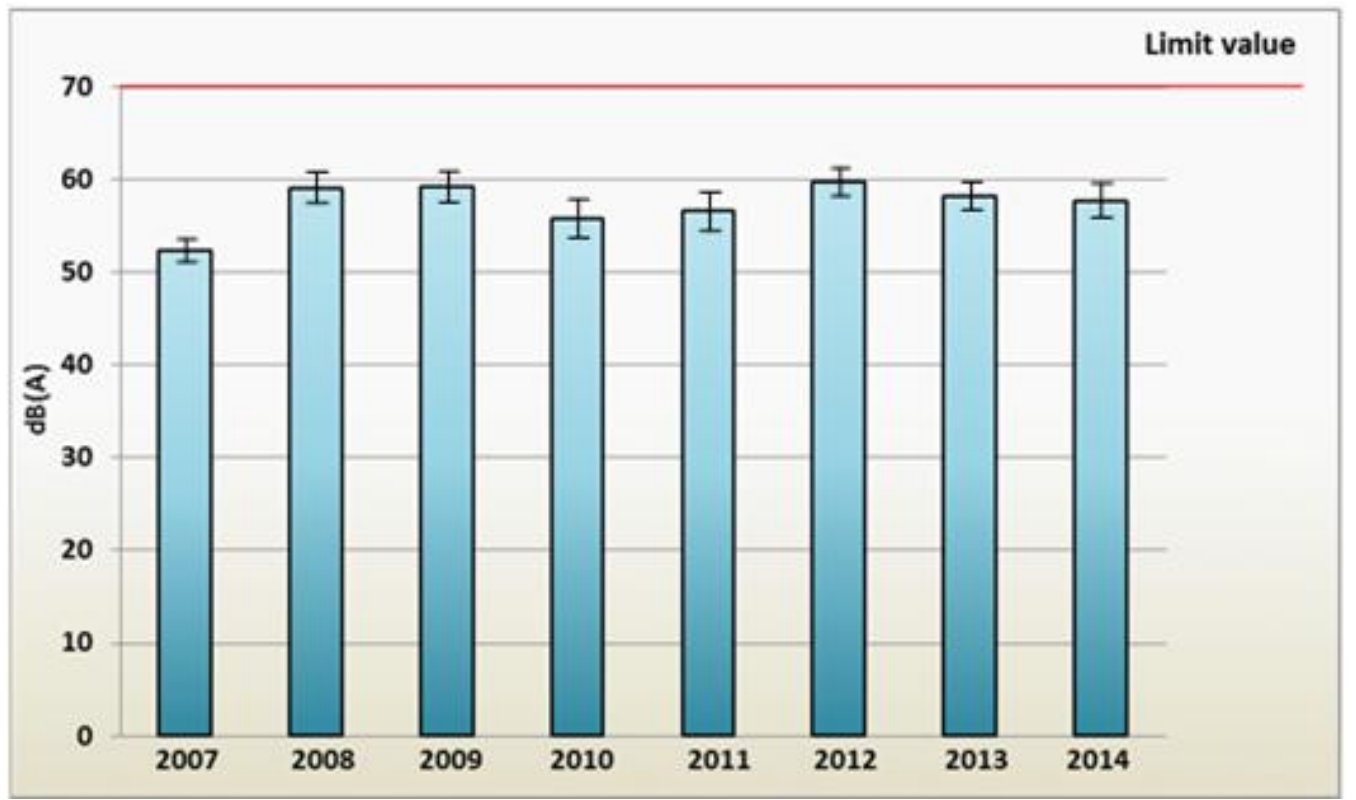

Fig. 6: Average LeqD at industrial areas, $d B(A)$

At built-up areas the average LeqD are slightly below the established limit value $-55 \mathrm{~dB}(\mathrm{~A})$ (Fig. 7). The lowest value is registered in $2010-49.36 \mathrm{~dB}(\mathrm{~A})$ and the highest sound levels are registered in $2008-55.55 \mathrm{~dB}(\mathrm{~A})$ and in 2012 - $55.69 \mathrm{~dB}(\mathrm{~A})$ as they exceed the limit value negligibly. From 2010 onwards a statistically reliable increase of the average LeqD is registered during the period 2012-2014 as the differences are of strong statistical significance $(\mathrm{P}<0.001)$.

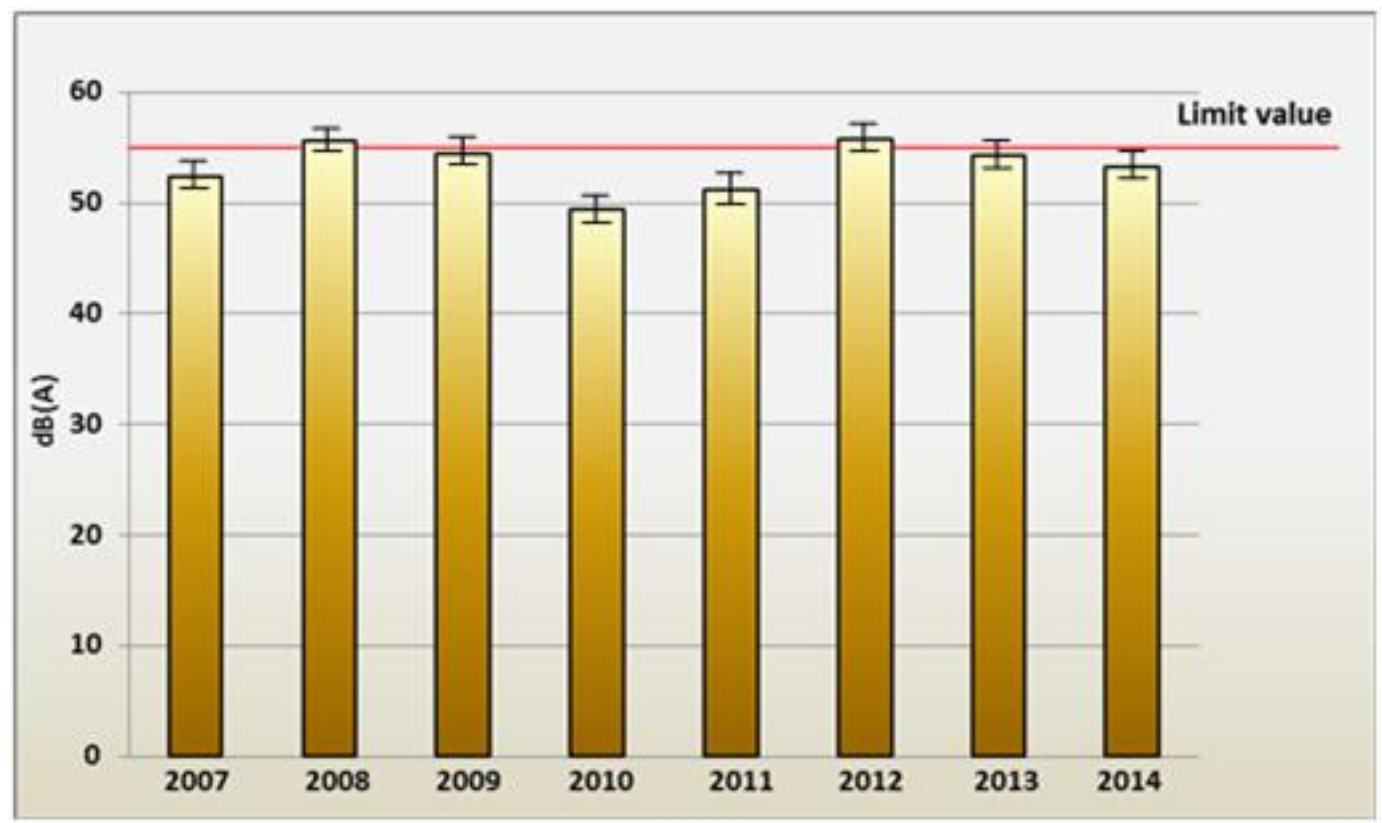

Fig. 7: Average LeqD at built-up areas, $\mathrm{dB}(\mathrm{A})$

At recreation areas the average LeqD exceed the established limit value $-45 \mathrm{~dB}(\mathrm{~A})$ during the entire monitoring period (Fig. 8). The registered sound levels vary from 47.26 to $55.55 \mathrm{~dB}(\mathrm{~A})$ as they exceed the limit value with 2 to 10 $\mathrm{dB}(\mathrm{A})$. At the beginning of the monitoring period (2007) the average LeqD is $51.52 \mathrm{~dB}(\mathrm{~A})$, slightly increases to 52.24 $\mathrm{dB}(\mathrm{A})$ during the next years and drops to $47.26 \mathrm{~dB}(\mathrm{~A})$ in 2010 still being $2 \mathrm{~dB}(\mathrm{~A})$ above the limit value. During the next years the average LeqD slightly increases to 55.22
$\mathrm{dB}(\mathrm{A})$ in 2012 and still exceeds the limit value at the end of the monitoring period (2014) - 51.78 $\mathrm{dB}(\mathrm{A})$. The registered increase trend from 2010 onwards is statistically reliable as the differences are of strong statistical significance $(0.001 \leq$ $\mathrm{P} \leq 0.05)$.

It is an annoying fact that recreation areas are noise polluted and the exposed population might be affected negatively.

Similar results are registered at hospitals and sanatoria. The average LeqD exceed the limit value $-45 \mathrm{~dB}(\mathrm{~A})$ during the 
entire monitoring period except in 2010 when the average LeqD is close to the limit value $-44.55 \mathrm{~dB}$ (A) (Fig. 9). The registered sound levels vary from 49.30 to $56.38 \mathrm{~dB}(\mathrm{~A})$ and exceed the established limit value with 4 to $11 \mathrm{~dB}(\mathrm{~A})$. From
2010 onwards the environmental noise pollution increases as the differences are of strong statistical significance $(0.01 \leq \mathrm{P}$ $\leq 0.05)$.

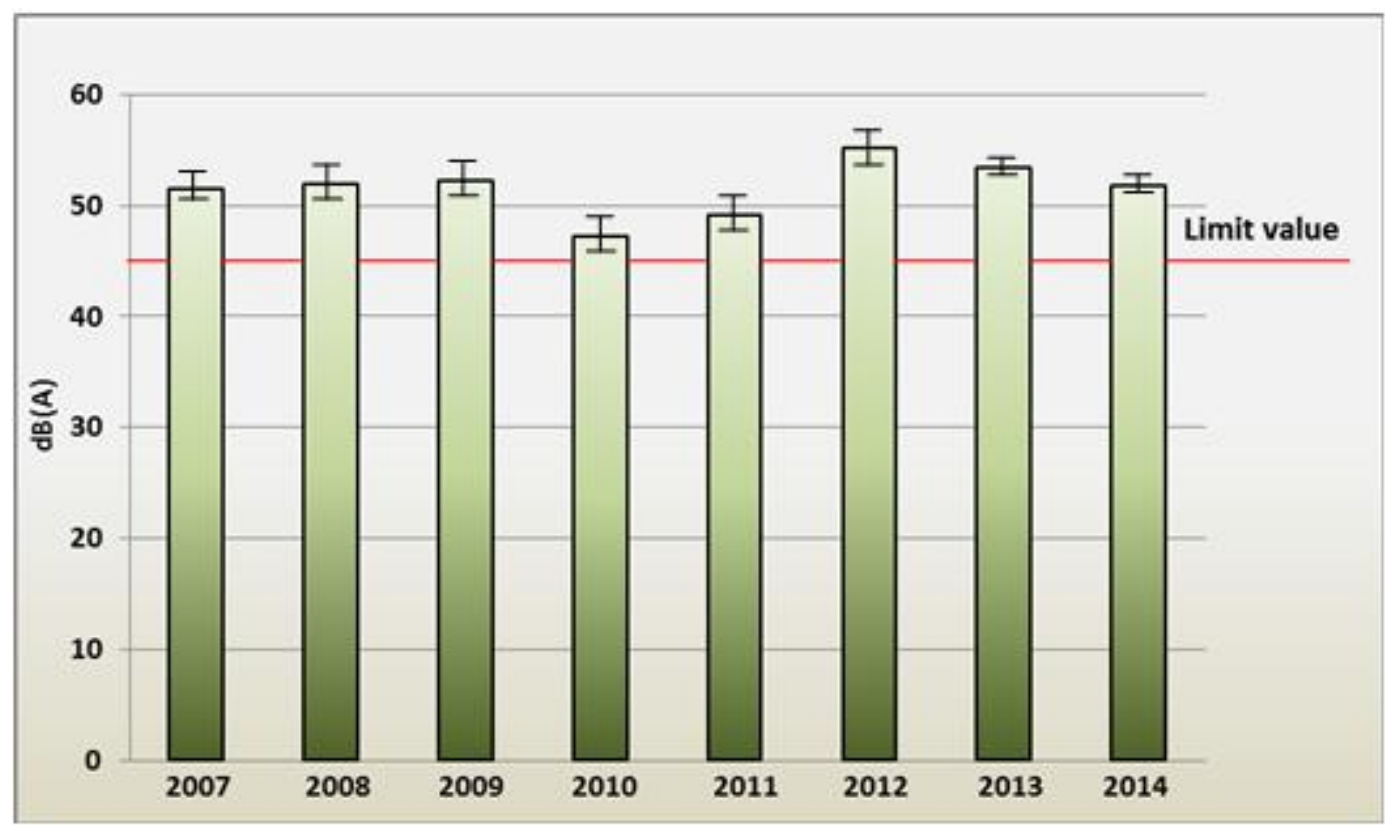

Fig. 8: Average LeqD at recreation areas, $d B(A)$

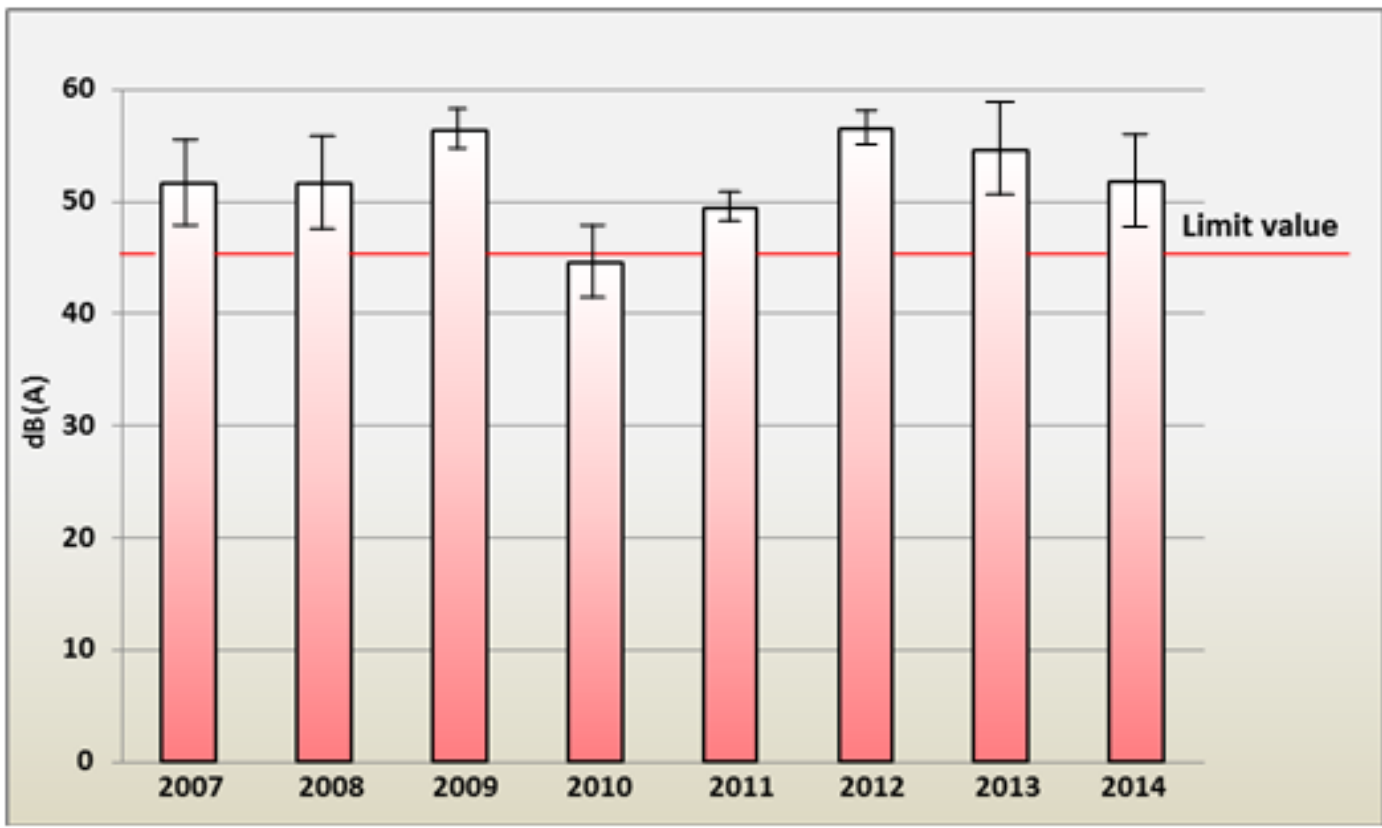

Fig. 9: Average LeqD at hospitals and sanatoria, dB(A)

The average LeqD at scientific research sites exceed the limit value $-45 \mathrm{~dB}(\mathrm{~A})$ except in 2010 when $41.03 \mathrm{~dB}(\mathrm{~A})$ is registered (Fig. 10). The measured sound levels vary between 49.40 and $52.40 \mathrm{~dB}(\mathrm{~A})$ and exceed the established limit value with 5 to $7 \mathrm{~dB}(\mathrm{~A})$. From 2010 onwards a significant noise pollution is registered as the differences are of strong statistical significance $(\mathrm{P}<0.05)$. 


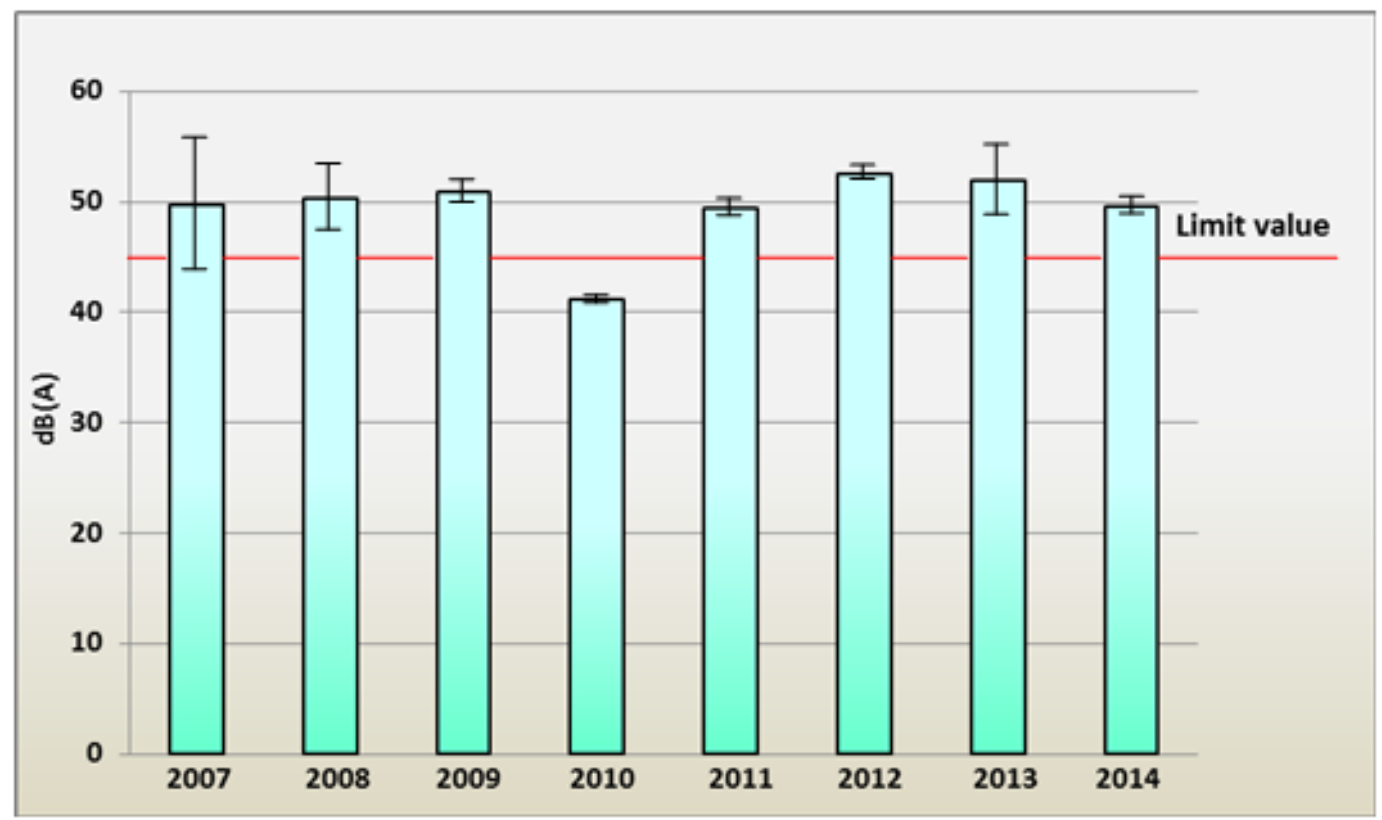

Fig. 10: Average LeqD at scientific research sites, $d B(A)$

At quiet areas in open country there is a significant noise pollution during the entire monitoring period. At the beginning of the period (2007-2009) the average LeqD vary from 40.30 to $42.84 \mathrm{~dB}(\mathrm{~A})$ and exceed the established limit value with $3 \mathrm{~dB}(\mathrm{~A})$ (Fig. 11). The lowest average LeqD is registered in $2010-33.70 \mathrm{~dB}(\mathrm{~A})$ and only then the limit value is not exceeded. From 2010 onwards there is a slight increase trend and the average LeqD in 2014 is $47.73 \mathrm{~dB}(\mathrm{~A})$ as the differences are of strong statistical significance $(0.001$ $\leq \mathrm{P} \leq 0.05$ ). The registered noise pollution outside urban areas requires the adoption of adequate reduction measures.

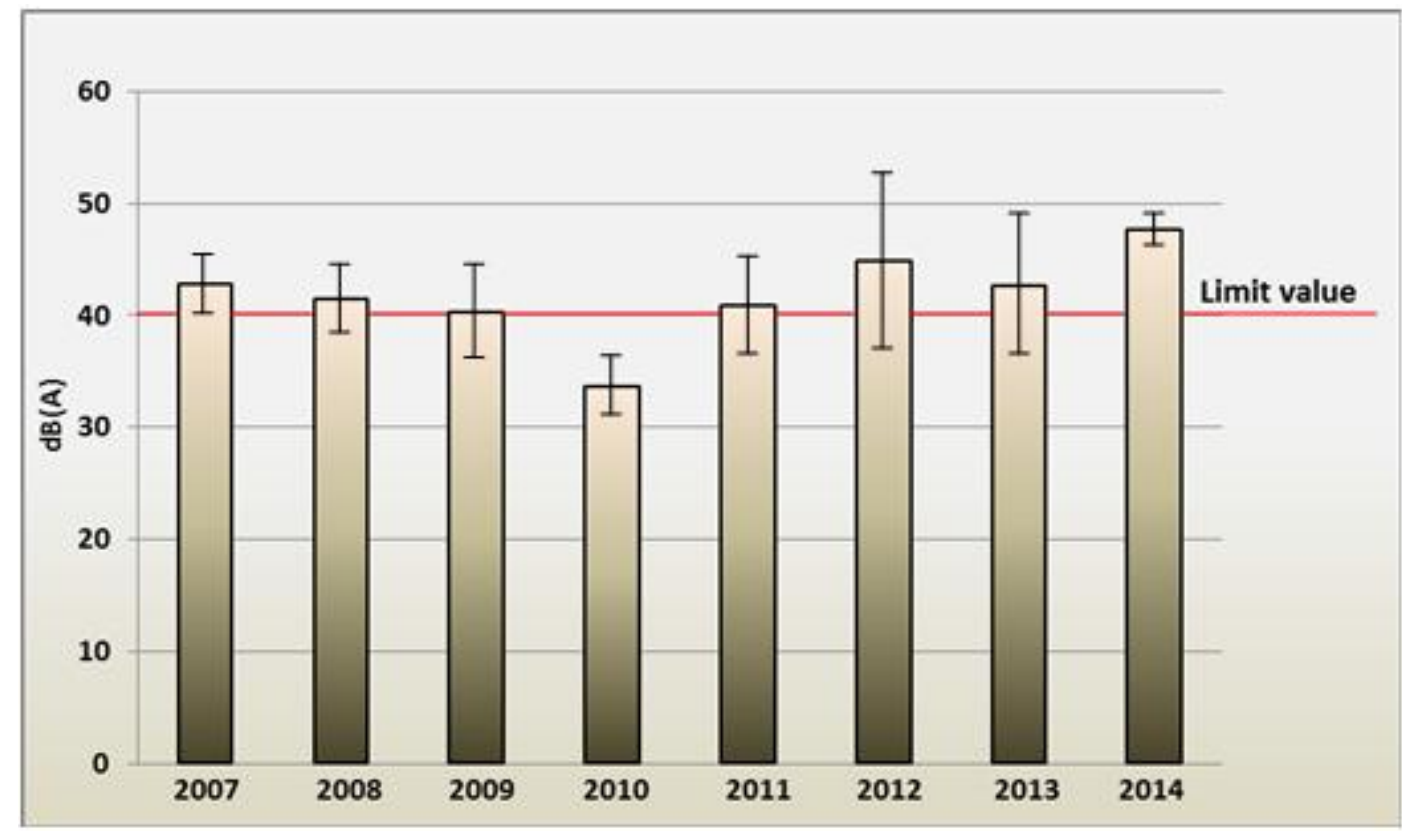

Fig. 11: Average LeqD at quiet areas in open country, $\mathrm{dB}(\mathrm{A})$

The distribution of the registered sound levels according to their range for the period 2007-2014 is indicated on Table 1. Results indicate that posts with noise pollution within the range 58-62 $\mathrm{dB}(\mathrm{A})$ increase their share in $2014-31.11 \%$ compared to that in $2013-6.7 \%$. Posts with noise pollution within that range have inconsiderable share during the previous years - from 2.2 to $13.3 \%$. A similar increase trend is registered regarding posts with noise pollution within the range $63-67 \mathrm{~dB}(\mathrm{~A})-13.3 \%$ of the posts in 2014 register sound levels within that range against $8.9 \%$ in 2013 . The registered noise pollution within the range 63-67 $\mathrm{dB}(\mathrm{A})$ varies from 4.4 to $11.1 \%$ during the monitoring period. A significant drop is registered regarding sound levels below $58 \mathrm{~dB}(\mathrm{~A})-42.2 \%$ in 2014 against $60-66 \%$ during the previous years. 
Table 1: Distribution of noise pollution according to the range, $\%$

\begin{tabular}{|c|c|c|c|c|c|}
\hline Year & Below 58 dB(A) & $\mathbf{5 8 - 6 2 ~ d B ( A ) ~}$ & $\mathbf{6 3 - 6 7} \mathbf{d B}(\mathbf{A})$ & $\mathbf{6 8 - 7 2} \mathbf{~ d B}(\mathbf{A})$ & $\mathbf{7 3 - 7 7} \mathbf{d B}(\mathbf{A})$ \\
\hline 2007 & 44.4 & 22.2 & 4.4 & 22.2 & 6.7 \\
\hline 2008 & 53.3 & 13.3 & 3.7 & 20.0 & 6.7 \\
\hline 2009 & 55.6 & 8.9 & 8.9 & 24.4 & 2.2 \\
\hline 2010 & 66.7 & 2.2 & 11.1 & 17.8 & 2.2 \\
\hline 2011 & 64.4 & 2.2 & 4.4 & 24.4 & 4.4 \\
\hline 2012 & 53.3 & 13.3 & 8.9 & 17.8 & 6.7 \\
\hline 2013 & 60.0 & 6.7 & 8.9 & 20.0 & 4.4 \\
\hline 2014 & 42.2 & 31.1 & 13.3 & 8.9 & 4.4 \\
\hline
\end{tabular}

During the past few years various measures have been adopted: redirection of commercial traffic outside urban areas, major roads reconstruction, road surface repair, cultivation of green strips along roads, speed limitation at built-up areas, etc., but they have not resulted in noise pollution reduction. Major noise pollution is registered at certain roads as the measured sound levels exceed the limit value though one-way traffic has been established and the traffic flow intensity has not increased.

General Annual Report on Noise Pollution at Urban Areas [23] and National State of the Environment Report [17] indicate that the registered sound levels exceed the established limit values at $73 \%$ of the posts in the scope of Bulgarian National Monitoring System for Environmental Noise Monitoring. The number of the posts where limit values are exceeded grows compared to 2012. Another adverse factor is that the number of posts with noise pollution within the range $63-37 \mathrm{~dB}(\mathrm{~A})$ increases with $33 \%$ compared to 2012. Varna is one of the agglomerations with increased number of posts where registered sound levels exceed the established limit values.

The EU Committee of the Regions recommends the adoption of measures mostly at public transport sector, including underground transport systems, walking and cycling alleys, speed limitation, reduction of the traffic flow intensity, etc. An increasing number of agglomerations adopt measures to relieve traffic congestion by giving advantage to pedestrians and cyclists [24, 25]. From 2010 onwards Varna Municipality applies an Action Plan on prevention and reduction of environmental noise pollution [26]. The environmental noise pollution has been analyzed on the basis of 60 points that define the major sources of noise pollution at the agglomeration, the main reasons for exceeding the established sound level limit values, the dynamics and the spatial distribution of noise pollution levels, the number and the share of the exposed population, etc. Within the Strategic Noise Map [27] the registered values of the noise indicators $\mathrm{L}_{24}$ (the day-evening-night noise indicator for overall annoyance) and $\mathrm{L}_{\text {night }}$ (the nighttime noise indicator for sleep disturbance from road traffic, railroad transport, aviation and industry) are indicated. The short-term prognosis, defined in Varna Municipality Development Plan 2014-2020 [28], indicates an increase of the registered environmental noise pollution due to more intensive traffic flow and higher levels of economic activity. In order to reduce the environmental noise pollution it is of crucial significance to adopt effective measures, such as:
- Optimization of road traffic;

- Optimization of aviation;

- Improvement of the road surface quality;

- Control pursuant to national legislation.

Similar adequate measures for noise pollution reduction are set in the Action Plan on prevention and reduction of environmental noise pollution.

\section{CONCLUSIONS}

The major source of environmental noise pollution in Varna is road traffic - at posts with intensive road traffic the registered sound levels exceed considerably the established limit value. At recreation areas and quiet areas in open country noise pollution limit values are exceeded as well. For that reason measures are adopted towards urban planning pursuant to the General Urban Plan of Varna [29]. The general principle at transport and communication planning is redirection of road traffic from city center to the outskirts. Building a cycling alley network from the suburbs to the city center of Varna that is designed to take $5-10 \%$ of the current car traffic is a measure for environmental noise reduction. If the expected level of cycling traffic is achieved it will compensate the increase of environmental noise pollution due to the increased number of citizens using personal vehicles. Another noise reducing measure is even distribution of sufficient number of parking lots, not more than $50 \%$ of them for open air parking, that will lead to reduction of time for finding a parking lot in the city center (continuous car traffic caused by insufficient parking lots leads to deteriorated acoustic environment).

Some state-of-the-art measures to prevent traffic noise are noise absorbing walls made of one or more light materials (natural or recycled) that are environmentally friendly and comply the sustainable development requirements; mounds that cause simultaneous sound reflection and absorption; green areas that are suitable for urban areas and open country (the noise reducing effect depends on the green area dimensions, the thickness, width and type of the plants).

The planned transformation of transport and communication structure of Varna will result in redirection of the car traffic outside the city center. The adoption of some additional measures as acoustic screens and noise absorbing walls will lead to environmental noise reduction that will compensate the adverse effects of increased motorization and increased number of citizens. 


\section{ACKNOWLEDGEMENT}

The authors are thankful to all specialists from the Regional Health Inspection in Varna for their expertise.

\section{REFERENCES}

[1] Directive 2002/49/EO of the European Parliament and of the Council of 25 June 2002 relating to the assessment and management of environmental noise, (2002). OJ L 189, 12-25.

[2] Environmental noise prevention law, (2005). Governmental Newsletter, 2005 (74), amendments 2014 (98).

[3] Environment protection law, (2002). Governmental Newsletter, 2002 (91), amendments 2014 (98)

[4] Mihailov, B.; Georgiev, M.; Gadeleva, A., (2011). Strategic noise mapping for Sofia agglomeration. Ecological Engineering and Environment Protection, 2011 (2), 4-16.

[5] Mihailov, B.; Ivanova, T.; Georgiev, M., (2012). Strategic noise mapping and action planning for agglomerations with over 100 thousand inhabitants highlights from realized projects. Ecological Engineering and Environment Protection, 2012 (1), 6369.

[6] Petkov, T. An attempt for analysis of strategic noise maps and action plans in the view of aviation noise, (2012). Ecological Engineering and Environment Protection, 2012 (1), 70-75.

[7] Georgiev, M.; Mihailov, B. (2012) Continuous monitoring and periodic capture for acoustic environment and noise pollution in urban areas. Ecological Engineering and Environment Protection, 2012 (1), 59-62.

[8] The Health Effects of Environmental Noise - Other than Hearing Loss, (2004). Commonwealth of Australia.

[9] WHO (2011). Burden of Disease from Environmental Noise. WHO Regional Office for Europe, Copenhagen, Denmark.

[10] Kim, M.; Chang, S. I.; Seong, J. C.; Holt, J. B.; Park, T. H.; Ko, J. H.; Croft, J. B., (2012). Road traffic noise: annoyance, sleep disturbance and public health implications. American Journal of Preventive Medicine, 43 (4), 353-360.

[11] Balashanmugam, P.; Ramanathan, A. R.; Nehrukumar, V.; Balasubramaniyan, K., (2013). Assessment of noise pollution in Chidambaram town. International Journal of Research in Engineering and Technology, 2 (10), 85-93.

[12] Murthy, E.; King, E., (2014). Environmental Noise Pollution. $1^{\text {st }}$ Ed. Elsevier.

[13] Tobias, A.; Recio, A.; Diaz, J.; Linares, C., (2015). Health impact assessment of traffic noise in Madrid (Spain). Environmental Research, 137, 136-140.

[14] Stansfeld, S.; Crombie, R., (2011). Cardiovascular effects of environmental noise. Noise Health, 13 (52), 229-233.

[15]EEA Report No 10, Noise in Europe, (2014). Copenhagen, Denmark.
[16] The European environment - state and outlook 2015 synthesis report, (2015). European Environment Agency, Copenhagen, Denmark.

[17] National state of the environment report, (2012), (2013). Executive Environment Agency, Sofia, Bulgaria.

[18] Guideline methodology for the determination of the number, situation and spatial distribution of posts for environmental noise monitoring and the intervals for sound level measurements and/or calculations, (2007). Ministry of Health, Sofia, Bulgaria.

[19]Regulation No 54 relating to the functioning of the national system for environmental noise monitoring and on the requirements for monitoring conduction and information submission from industrial sources of environmental noise, (2011). Governmental Newsletter, 2011 (3).

[20] Padshala, A., (2014). Traffic Studies of Urban MidBlock Section: A Case Study of Pragatinagar to Akhbarnagar and Akhbarnagar to Ranip Cross Road. International Journal of Research in Engineering and Technology, 3 (6), 383-385.

[21] Regulation No 6 on environmental noise indicators defining the degree of discomfort during different parts of the day, the limit values for environmental noise indicators, the assessment methods for environmental noise indicators and harmful effects of noise upon human health, (2006). Governmental Newsletter, 2006 (58).

[22] Murthy, V. K.; Majumder, A. K.; Khanal, S. N.; Subedi, D. P., (2007). Assessment of traffic noise pollution in Banepa, a semi urban town of Nepal. Kathmandu University Journal of Science, Engineering and Technology, I (IV), 1-10.

[23] General report on noise pollution at urban areas, (2012), (2013). Ministry of Environment and Water, Sofia, Bulgaria.

[24] Bronson, R.; Marshall, W., (2014). Alternative and adaptive transportation: What household factors support recovery from a drastic increase in gas price? International Journal of Environmental Science and Technology, 11 (8), 2245-2258.

[25] Faherty, T. R.; Morrisey, J. E., (2014). Challenges to active transport in a car-dependent urban environment: a case study of Aucklsnd, New Zealand. International Journal of Environmental Science and Technology, 11 (8), 2369-2386.

[26] Action Plan on management, prevention and reduction of environmental noise pollution at Varna agglomeration, (2010). Varna, Bulgaria.

[27] Strategic noise map of Varna (2008). Varna, Bulgaria.

[28] Varna Municipality Development Plan 2014-2020, (2013). Municipal Council Decision No 1124-9, Varna, Bulgaria

[29] General urban plan of Varna Municipality, (2012). Varna, Bulgaria.

[30]Röösli, M., (2013). Health effects of environmental noise exposure. Ther Umsch, 70 (12), 720-724. 